\title{
ASSISTÊNCIA TÉCNICA PARA HABITAÇÃO DE INTERESSE SOCIAL: Sua inserção como instrumento da política urbana em planos diretores municipais no Brasil
}

\author{
TECHNICAL ASSISTANCE FOR SOCIAL HOUSING: \\ Its insertion as an instrument of urban policy in Brazilian municipal \\ master plans
}

\author{
A. Maressa Fonseca e Souza \\ Centro Universitário de Viçosa - UNIVIÇOSA; Brasil \\ Universidade Federal de Viçosa, Brasil \\ maressa.arq@gmail.com \\ maressa.fs@gmail.com
}

\section{RESUMO}

O artigo tem o objetivo de refletir sobre a presença da assistência técnica em habitações de interesse social (ATHIS) como diretriz em planos diretores municipais, sendo a ATHIS entendida como um instrumento da política urbana para democratização da gestão urbana e do direito à moradia. Tomou-se cinco municípios em que a ATHIS foi incorporada em diretrizes propostas nos respectivos planos; a partir da análise das disposições, acredita-se que não há um consenso sobre as atribuições a que se refere a assistência técnica nos planos diretores analisados. Em municípios em que os planos diretores propuseram a criação de programas de ATHIS, verificou-se que foram aprovadas leis municipais para a criação dos mesmos. Contudo, em outros casos, foram observados entraves à consolidação da ATHIS, o que leva ao questionamento se há ausência de recursos financeiros ou de vontade política para efetivar as ações.

Palavras-chave: assistência técnica, habitação de interesse social, plano diretor, política urbana.

Linha de Investigação: 1: Cidade e projeto,

Tópico: Habitação e projeto residencial

\section{ABSTRACT}

The paper aims to reflect on the presence of technical assistance for social housing (ATHIS) as a guideline in municipal master plans. Technical assistance is understood as an instrument of urban policy to democratize urban management and the right to housing. Five municipalities were taken in which ATHIS was incorporated 


\section{SÃOPAULO15 $17 \cdot$ LISBOA $25 \sim 26$ JUN 2020}

into the guidelines proposed in the respective plans. From the analysis of the provisions, it is believed that there is no consensus on the attributions to which technical assistance refers. In municipalities where the master plans proposed the creation of ATHIS programs, it was found that municipal laws were approved for their creation. However, in other cases, obstacles to the consolidation of ATHIS were observed, leading to the question of whether there is an absence of financial resources or political will to carry out the actions.

Keywords: technical assistance, social housing, master plan, urban policy.

Research line: 1. City and design

Topic: Housing and residential design

\section{Introdução}

Desde 1948, o direito à moradia digna foi reconhecido como pressuposto para a dignidade humana pela Declaração Universal dos Direitos Humanos. No Brasil, a moradia digna passou a ser efetivamente reconhecida como direito humano pelo Estado em 2000, a partir da Emenda Constitucional no 26. Faz parte da trajetória de luta pela efetivação do acesso à moradia digna a implementação da assistência técnica para habitação de interesse social (ATHIS), a qual visa assegurar este direito para famílias de baixa renda.

Em 2001, com a aprovação do Estatuto da Cidade (Lei Federal no 10.257), foi estabelecido um conjunto de instrumentos para que municípios possam construir uma política urbana que concretize a função social da propriedade urbana e o direto à cidade. O principal instrumento da política urbana estabelecido pelo Estatuto foi o plano diretor, que reúne os demais instrumentos para estabelecer como cada porção do território deve cumprir a sua função social. Dentre eles, a assistência técnica e jurídica gratuita para comunidades e grupos sociais menos favorecidos se insere como um instrumento jurídico e político da política urbana (Art. 4, alínea r) voltado para a democratização da gestão urbana e do direito à moradia (Carvalho; Rossbach, 2010).

A assistência técnica foi efetivamente regulamentada no Brasil por meio da Lei Federal 11.888/08, que assegura às famílias com renda mensal de até 3 (três) salários mínimos assistência pública e gratuita para o projeto e a construção da habitação de interesse social. Segundo este marco regulatório, entende-se "assistência técnica" como os trabalhos de projeto, acompanhamento e execução de obras necessários para edificação, reforma, ampliação ou regularização fundiária da habitação realizados por profissionais de arquitetura, urbanismo e engenharia. A Lei prevê o apoio financeiro do Estado para a execução dos serviços gratuitos de ATHIS, por meio da transferência de recursos do Fundo Nacional de Habitação de Interesse Social (FNHIS) para os Estados, o Distrito Federal, Municípios e entidades privadas sem fins lucrativos (Brasil, 2008). Em contrapartida, a Lei no 11.888 confere atribuições aos municípios para a efetivação da ATHIS.

A despeito dos benefícios possíveis a partir dessa legislação, ações neste âmbito ainda são muito incipientes: poucos municípios incorporaram institucionalmente a ATHIS como instrumento da política urbana e como forma de democratização do acesso à moradia digna. Assim, tomando como referência que o Estatuto da Cidade estabelece o plano diretor como principal instrumento da política urbana, a partir desse trabalho questiona-se: em que medida diretrizes presentes em planos diretores municipais propõem a ATHIS como forma de se concretizar o acesso à moradia digna? 


\section{SÃO PAULO15 $\sim 17 \cdot$ LISBOA $25 \sim 26$ JUN 2020

Segundo Saboya (2006), o plano diretor pode ser entendido como um documento que sintetiza e explicita objetivos consensuados para o município e estabelece princípios, diretrizes e normas a serem utilizados como base para que decisões de atores envolvidos no processo de planejamento urbano sigam na direção destes objetivos. Para Stephan et. al. (2008), mais do que um documento técnico, a partir da aprovação do Estatuto da Cidade, o plano diretor consiste em um espaço de debate dos cidadãos e de definição de opções por estratégias de intervenção no território, sendo a participação é fundamental neste processo. O plano diretor deve visar, segundo o Estatuto da Cidade, a distribuição justa de benefícios e ônus do processo de urbanização através de mecanismos que reduzam a segregação social, como a regularização fundiária e urbanização de assentamentos precários, visando efetivar o direito à moradia digna.

Tendo em vista tais pressupostos, a política urbana, assim como qualquer política pública, necessita de meios efetivos para a sua materialidade. Segundo Alvim e Castro (2010), as políticas públicas partem de um nível mais abstrato, de diretrizes que traduzem intenções em relação a práticas e demandas sociais, para um nível mais concreto de atendimento a estas demandas, o nível da produção de efeitos, portanto partem do direito em direção à materialidade. Haveria assim uma sequência processos para se chegar à materialidade das políticas públicas, sendo eles: política, planos, programas/projetos, ações concretas e efeitos. As ações concretas podem se traduzir na produção de processos (participação, aprovação, procedimentos), de fatos (eventos, conjunto de eventos encadeados) ou objetos materiais (obras, objetos). Já os efeitos consistem nos múltiplos resultados destas ações, sejam eles intencionais ou não.

Partindo destes pressupostos, busca-se neste artigo identificar diretrizes para ações voltadas à ATHIS presentes em planos diretores municipais, bem como a implementação de programas ou projetos que viabilizem a materialidade da ATHIS como política pública. Entende-se que a presença de diretrizes sobre ATHIS em um plano diretor corrobore a criação e orientação de ações concretas e efeitos, contribuindo para a efetivação das ações de assistência técnica em esfera municipal.

\section{Procedimentos metodológicos}

Foram realizadas pesquisas documental e bibliográfica para analisar a inserção da assistência técnica em planos diretores municipais. Para tanto, recorreu-se à investigação em sites de pesquisa, como Google e Google Scholar, utilizando termos de busca como "plano diretor + assistência técnica + habitação". Os resultados apresentaram, principalmente, notícias sobre ações voltadas para a ATHIS em municípios, o que direcionou à busca por planos diretores dos mesmos e a procura pelo termo "assistência técnica" nos textos. Foi possível encontrar as leis dos planos diretores vigentes nos sites das respectivas prefeituras, já em domínios onde se catalogam legislações disponíveis online, como Jusbrasil.com.br e Leismunicipais.com.br, foi possível acessar documentos referentes aos planos diretores anteriores à última revisão feita nos municípios.

Todos os planos diretores encontrados datam de momentos posteriores à aprovação do Estatuto da Cidade, sendo que apenas um dos planos vigentes é anterior a aprovação da Lei 11.888/2008, devido à tramitação do processo de revisão ter sido interrompida por ação do Ministério Público. O critério de seleção se deu pela possibilidade de acesso à lei na íntegra, em formato de texto digital e disponível na Web, e pela facilidade de se realizar a busca do termo "assistência técnica" através da ferramenta de busca por palavras. Por este motivo, não foram selecionados planos diretores digitalizados apenas em formato de imagem (escaneados). 


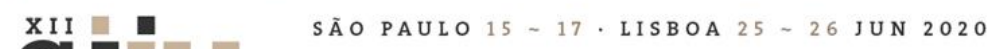 \\ Seminário Internacional de Investigação em Urbanismo \\ Seminario Internacional de Investigación en Urbanismo}

A partir da busca realizada, foram selecionados os planos diretores de cinco municípios brasileiros, a saber, Uberlândia (MG), Curitiba (PR), Salvador (BA), Ribeirão Preto (SP) e Campinas (SP), sendo consideradas as leis aprovadas e em vigor no momento em que a pesquisa foi realizada (Junho de 2018).

\section{Resultados}

O Quadro 1 apresenta uma sistematização das informações, onde se identificam os municípios e suas respectivas legislações (planos diretores), as disposições que os respectivos planos trazem sobre a ATHIS e algumas observações acerca de ações desenvolvidas nos respectivos municípios para efetivação das diretrizes propostas, bem como eventuais entraves a estas realizações, neste sentido, buscou-se verificar se as ações voltadas para ATHIS já estavam previstas nos planos diretores anteriores à última revisão, se foi criado algum programa ou se foram instituídas ações em nível municipal para realização do serviço e outros aspectos relevantes. No Quadro 1 são disponibilizados, também, os endereços eletrônicos para o acesso aos documentos citados, como encontrados na Web no momento de realização da pesquisa documental. Além disso, as disposições encontradas nos planos diretores acerca da assistência técnica como diretriz da política urbana são destacadas em negrito.

\begin{tabular}{|c|c|c|}
\hline Município / Lei & Disposições sobre ATHIS & Observações \\
\hline $\begin{array}{l}\text { Lei }{ }^{\circ} 432 / 2006 \\
\text { (Aprova o Plano Diretor do } \\
\text { município de Uberlândia, } \\
\text { estabelece os princípios } \\
\text { básicos e as diretrizes para } \\
\text { sua implantação, revoga a lei } \\
\text { Complementar no } 078 \text { de } 27 \\
\text { de abril de } 1994 \text { e dá outras } \\
\text { providências.) }\end{array}$ & $\begin{array}{l}\text { TITULO II - DAS DIRETRIZES E AÇÖES DE DESENVOLVIMENTO } \\
\text { Capítulo VIII - Das políticas sociais públicas } \\
\text { - Art. 41: Diretrizes da política habitacional: IV - viabilizar parcerias } \\
\text { de assistência técnica gratuita com entidades para o } \\
\text { desenvolvimento de programas de interesse social, autoconstrução } \\
\text { e regularização; } \\
\text { - Art. 42: Ações de desenvolvimento da política habitacional: VIII - } \\
\text { estudar alternativas de assistência técnica para programas de } \\
\text { interesse social. }\end{array}$ & $\begin{array}{l}\text { - O projeto de lei de revisão do Plano } \\
\text { Diretor (PL n }{ }^{\circ} 023 / 2017 \text { ) traz o incentivo } \\
\text { ao serviço de ATHIS como uma das } \\
\text { diretrizes da política de desenvolvimento } \\
\text { urbano (Art. 19, inciso XIII), mas suprime } \\
\text { as diretrizes presentes no PD de } 2006 \text {. } \\
\text { - Em } 2017 \text { foi firmado um TAC entre } \\
\text { Ministério Público de Minas Gerais } \\
\text { (MPMG) e Prefeitura de Uberlândia para } \\
\text { realização de regularização fundiária de } \\
\text { assentamos urbanos e de serviços de } \\
\text { ATHIS no município. } \\
\text { - Em abril de } 2018 \text { o MPMG recomendou } \\
\text { suspender a tramitação da revisão do } \\
\text { Plano Diretor devido ao não } \\
\text { cumprimento de exigências quanto a } \\
\text { participação popular. }\end{array}$ \\
\hline $\begin{array}{l}\text { Lei }{ }^{\circ} 14.771 / 2015 \\
\text { (Dispõe sobre a revisão do } \\
\text { Plano Diretor de Curitiba de } \\
\text { acordo com o disposto no } \\
\text { art. } 40, \S 3 \text {, do Estatuto da }\end{array}$ & $\begin{array}{l}\text { TITULO III - DA POLÍTICA URBANA } \\
\text { Capítulo V - Da habitação } \\
\text { - } \quad \text { Art. 80: Promover a assistência técnica e jurídica gratuitas para } \\
\text { a população de baixa renda, nos termos da legislação federal. } \\
\text { - Parágrafo único: A assistência técnica será destinada aos } \\
\text { projetos e execução de habitações de interesse social para famílias } \\
\text { de baixa renda em projetos de interesse coletivo, de forma pública }\end{array}$ & $\begin{array}{l}\text { - O Plano Diretor de } 2004\left(\underline{\text { Lei } n^{\circ}}\right. \\
11.266 / 2004) \text { apresentava a ATHIS } \\
\text { como diretriz da política de HIS a ser } \\
\text { prestada em ocupações irregulares } \\
\text { visando à regularização da ocupação. } \\
\text { - Em } 2017 \text { foi proposto um projeto de lei } \\
\text { para regulamentação da assistência } \\
\text { jurídica e técnica para projeto de } \\
\text { construção de HIS no município. }\end{array}$ \\
\hline
\end{tabular}




\section{SÃOPAULO15 17 LISBOA $25 \sim 26$ JUN 2020 \\ Seminário Internacional de Seminario Internacional de Investigação em Urbanismo Investigación en Urbanismo}

Cidade, para orientação e

controle do desenvolvimento

Integrado do Município).

\section{Salvador (BA):}

\section{Lei $n^{0} 9.069 / 2016$}

(Dispõe sobre o Plano Diretor de Desenvolvimento Urbano do Município de Salvador - PDDU 2016 e dá outras providências.)

\section{Ribeirão Preto (SP)}

\section{Lei $n^{\circ} 68 / 2017$}

(Dispõe sobre a revisão do Plano Diretor implantado pela Lei Complementar $n^{\circ}$ 501 , de 31 de outubro de 1995 e modificado pela le complementar $n^{\circ}$ 1.573, de 13 de novembro de 2003, na forma que especifica, e dá outras providências.) e gratuita, a ser regulamentada em lei específica.

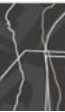

\section{TITULO VI - DA HABITAÇÃO}

Capítulo III - Das necessidades habitacionais:

- $\quad$ Art. 71: VI - Assistência técnica, urbanística, jurídica e social gratuita como instrumento para regularização fundiária de áreas ocupadas urbanizáveis;

- $\quad$ Art. 75: Programas de assistência técnica para elaboração e implantação de projetos de ampliação, reforma, melhoria da qualidade e das condições de salubridade da habitação, com a participação do interessado;

TÍTULO VIII - DO ORDENAMENTO TERRITORIAL

Capítulo VII - Dos instrumentos e da aplicação da política urbana do município:

- $\quad$ Art. 285: II - Instrumentos de planejamento e democratização da gestão urbana: c) Assistência técnica e jurídica gratuita para as comunidades e grupos sociais menos favorecidos;

TÍTULO IX - DO DESENVOLVIMENTO POLÍTICO-INSTITUCIONAL

Capítulo VII - Da educação para a cidadania:

- Art. 383: O Executivo proverá os meios para que a população participe ativamente da implementação da Política Urbana, compreendendo: I - Prestação de assistência técnica e jurídica gratuitas para as comunidades e grupos sociais menos favorecidos;

- $\quad$ Art. 384: Assistência técnica e jurídica gratuita será prestada a pessoas e entidades comprovadamente pobres, diretamente ou mediante convênio com instituições de ensino, organizações não governamentais ou com associações profissionais.

\section{Capítulo III - Da política urbana}

- Art. 7: III - Assistência técnica e jurídica gratuita para as comunidades e grupos sociais menos favorecidos como instrumento jurídico e político.

Capítulo VII - Do desenvolvimento social

- Art. 128: XI - Implantação de um programa de assistência técnica nas áreas de arquitetura, urbanismo e engenharia para construção de melhoria de habitações de interesse social como uma das diretrizes da política de habitação.
- O parecer da Câmara Municipal foi pelo arquivamento do projeto afirmando que o mesmo caracteriza a criação de política pública para direcionar ações do Poder Executivo, configurando em invação em atribuição privativa do Executivo.

- Em 2001 foi formalizado o Escritório Público dentro da extinta Secretaria de Habitação do município, que já desenvolvia serviços de ATHIS gratuita. Atualmente o Escritório integra a estrutura da Coordenadoria de Habitação da Secretaria Municipal de Infraestrutura e Obras Públicas SEINFRA.

- O Plano Diretor de 2008 já tratava sobre ATHIS em termos semelhantes ao atual (Lei $\left.n^{\circ} 7.400 / 2008\right)$.

- A Lei n ${ }^{\circ} 8.287 / 2012$ dispõe sobre a AT pública e gratuita no âmbito da arquitetura, urbanismo e engenharia para habitação de interesse social, voltada à população de baixa renda, portanto regulamenta as ações de ATHIS na esfera municipal em Salvador.

- O Plano Diretor de 2003 não tratava sobre ATHIS como instrumento da política urbana.

- A Lei $n^{0}$ 12.215/2010 instituiu o Programa Municipal de ATHIS.

\begin{tabular}{llr}
\hline Campinas (SP) & TíTULO I - DO PLANO DIRETOR E DA POLÍTICA DE DESENVOLVIMENTO & - O Plano Diretor de \\
& DO MUNICÍPIO & $\frac{15 / 2006}{2006}$ previa a AT como uma diretriz \\
& & da política de habitação do município, \\
Lei Complementar $\quad \mathrm{n}^{\circ}$ & Capítulo IX - Da habitação & porém não especificava a criação de \\
\hline
\end{tabular}




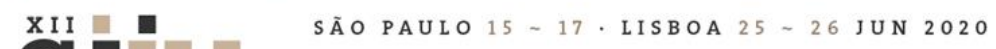

\begin{abstract}
$\underline{189 / 2018}$
(Dispõe sobre o Plano

Diretor Estratégico do

município de Campinas.)

- $\quad$ Art. 57: Implantação de programa de assistência técnica e financiamento para reforma, ampliação e melhoria da edificação, promovendo convênios com Cohab e com conselhos profissionais (CAU, CREA) e entidades ligadas à arquitetura e engenharia civil como uma das diretrizes da política de habitação.
\end{abstract}

- Assistência técnica, jurídica e social gratuitas como instrumento para viabilizar a regularização fundiária.

Quadro 1 - Municípios onde a ATHIS está prevista como instrumento no Plano Diretor. Fonte: Planos Diretores municipais e sites das respectivas prefeituras e câmaras municipais, consultados em Junho de 2018.

Dos municípios selecionados, observa-se que em Curitiba, Salvador, Ribeirão Preto e Campinas foram propostas leis para regulamentação das ações em ATHIS na esfera municipal. Em Campinas e Ribeirão Preto foram aprovadas leis para a criação de programas de assistência técnica no ano de 2010, apesar de os planos diretores vigentes à época não tratarem diretamente sobre a necessidade deste tipo de regulamentação. Ressalta-se que, em Ribeirão Preto, a ATHIS não estava mesmo presente como instrumento da política urbana no Plano Diretor. Os planos diretores atuais de ambos municípios incorporam as ações em ATHIS e a implantação de programas de assistência técnica como diretrizes da política de habitação.

No caso de Salvador, ações de assistência técnica já ocorriam desde 2001, quando foi criado o Escritório Público no âmbito da extinta Secretaria de Habitação do município, o qual permanece em atuação (Santos; Gonçalves, 2015). Nesse sentido, tanto o Plano Diretor de 2008 quando de 2016, confirmavam as ações de assistência técnica, sendo que o Pano mais recente também insere a ATHIS como meio de participação popular na implantação da política urbana e como forma de educação para a cidadania, dentro das diretrizes sobre o desenvolvimento político-institucional do município.

Em Curitiba, o Plano Diretor apresenta a ATHIS como diretriz da política urbana e afirma a necessidade de criação de lei municipal específica para sua regulamentação. Ao se consultar a legislação através do site da Câmara Municipal, encontraram-se três projetos de lei que foram propostos no município desde 2005, que visavam a criação de um programa de ATHIS e a regulamentação das ações, sendo que todos os projetos foram arquivados. Ao último projeto, proposto em 2017 (Projeto de Lei Ordinária no 005.00223.2017), o parecer da Câmara foi pelo seu arquivamento afirmando que o projeto caracterizava criação de política pública e direcionamento de ações ao Poder Executivo, configurando-se como invasão de atribuições privativas ao Executivo. Outra justificativa para o arquivamento se deu pelo fato do texto não apresentar impactos orçamentários e indicação de fontes de custeio das ações.

Em contato com a assessoria da vereadora que propôs o projeto de lei mencionado, afirmou-se que houve tentativa de recorrer do entendimento do parecer da Câmara Municipal:

Tentamos recorrer do entendimento do parecer apresentando decisões da suprema corte, argumentando que não haveria interferência no poder Executivo visto que não há redesenho dos órgãos deste poder. Entretanto o plenário da Casa legislativa votou pelo arquivamento do projeto. Diante deste contexto, enviamos o Projeto como sugestão ao Executivo, porém temos clareza que para ATHIS funcionar na prática teria de haver uma mobilização de várias esferas da sociedade, CAU, ONGs, universidade, Prefeitura, dentre outros... além de recursos das outras 


\section{SÃOPAULO15 $17 \cdot$ LISBOA $25 \sim 26$ JUN 2020}

esferas federativas. Portanto, em que pese a Lei Federal e o Plano Diretor, ainda há um longo caminho a ser percorrido (Sanson, 2018).

O projeto foi enviado como sugestão para criação da Lei pelo Executivo que regulamente a ATHIS, contudo, não foram encontradas notícias sobre a sua tramitação ou efetivação até o presente momento

No município de Uberlândia, algumas peculiaridades foram encontradas devido às ações do Ministério Público de Minas Gerais (MPMG). No que tange à assistência técnica, em 2016 foi firmado um Termo de Ajustamento de Conduta (TAC) entre MPMG, Prefeitura de Uberlândia e Conselho Estadual de Habitação e Urbanismo, visando a implantação de projeto de regularização fundiária de interesse social e assistência técnica, com objetivo de regularizar loteamentos localizados em áreas pertencentes ao Estado e ao município. Não se encontraram, contudo, informações sobre ações efetivas acerca do referido projeto. O MPMG também recomendou a suspensão da tramitação do documento de revisão do Plano Diretor de Uberlândia devido ao não cumprimento de exigências quanto à participação popular. No Plano Diretor vigente, de 2006, a ATHIS faz parte das diretrizes da política habitacional no sentido de se viabilizar parcerias com entidades e estudar alternativas de assistência técnica em programas de HIS. Já na revisão do Plano Diretor, de 2017, estas diretrizes foram suprimidas, apresentando-se o incentivo ao serviço de ATHIS como uma diretriz da política de desenvolvimento urbano.

Observa-se que a assistência técnica é mencionada de três formas nos planos diretores analisados, a saber, i) como assistência técnica e jurídica, ii) como assistência técnica para projetos, construção e melhoria de HIS e iii) como assistência técnica, urbanística, jurídica e social. Elencando estes termos como mencionados nas leis analisadas, constata-se que há uma certa indefinição quanto aos serviços de assistência técnica ou do que se trata esta assistência dentro das políticas de habitação, de maneira que cada plano diretor a direciona as ações de maneira distinta.

No caso de Uberlândia, a ATHIS é voltada para programas de interesse social, autoconstrução e regularização; em Curitiba, para projetos e execução de HIS em processos de interesse coletivo. No plano de Salvador, é entendida como instrumento para regularização fundiária e para elaboração e implantação de projetos de ampliações, reforma e melhoria da qualidade e das condições de salubridade da habitação. Em Ribeirão Preto, a previsão de implantação de um programa de assistência técnica nas áreas de arquitetura, urbanismo e engenharia visa a construção e melhoria de HIS. Em Campinas, ocorre de maneira semelhante, porém, se acrescenta o financiamento ao programa e a promoção de convênios com entidades, e se tem as assistências técnica, jurídica e social como instrumento para regularização fundiária.

\section{Discussão}

Após realizada a pesquisa e a respectiva análise sobre a inserção da ATHIS nos planos diretores dos cinco municípios, dentre alguns achados relevantes é importante considerar certa imprecisão sobre o tipo de assistência técnica que está sendo tratada. Não se nega o aspecto interdisciplinar da assistência técnica ao se tratar da habitação de interesse social, uma vez que as ações em ATHIS, na escala urbana, têm envolvido outras disciplinas para além da arquitetura e da engenharia. A regularização fundiária, por exemplo, inserida no escopo da Lei 11.888/08, necessita de assistências técnica, jurídica, social e ambiental para que seja contemplada em sua totalidade. Em alguns planos, a inserção da assistência técnica é feita juntamente com 


\section{SÃO PAULO15 $\sim 17 \cdot$ LISBOA $25 \sim 26$ JUN 2020

assistências jurídica e social, o que pode suscitar uma falta de clareza sobre os serviços e atribuições profissionais necessárias.

É necessário reconhecer, contudo, que a própria Lei 11.888/08 deixa a desejar no que se trata desta interdisciplinaridade, uma vez que contempla apenas os serviços de arquitetura, urbanismo e engenharia. Além disso, ao se pensar na escala de intervenções, as demandas ocorrem tanto na escala da edificação quanto na escala urbana; portanto, as práticas e atribuições profissionais vão para além das atividades de projeto e execução propostas pela Lei. Neste sentido, o diagnóstico realizado no âmbito de elaboração do Plano Estratégico de Implementação da ATHIS (PEI-ATHIS), elaborado pelo Conselho de Arquitetura e Urbanismo de Santa Catarina (CAU/SC), aponta, pelo menos, seis ações de assistência técnica que envolvem múltiplos profissionais, as quais podem ser melhor especificadas em legislações municipais que tratem sobre o tema, sejam elas:

a) melhoria habitacional pontual,

b) melhoria da moradia total,

c) unidade habitacional nova + terra,

d) regularização fundiária,

e) qualificação de entorno / espaços públicos,

f) apoio técnico para a promoção da justiça e inclusão social nas cidades (CAU/SC, 2018).

Vale ressaltar, aqui, o empenho realizado nos últimos dois anos pelo Conselho de Arquitetura e Urbanismo do Brasil (CAU/BR), entidade que fiscaliza e regulamenta a atuação de arquitetos e urbanistas no país, no sentido de se promover a valorização das ações voltadas para ATHIS no país, por meio de eventos, debates entre profissionais, publicação de editais de apoio financeiro a entidades, bem como diversas ações desenvolvidas nas esferas de estaduais do Conselho. O supracitado PEI-ATHIS, apoiado pelo CAU/SC, suscitou não apenas um diagnóstico de experiências no Brasil, como tem elevado os debates acerca da assistência técnica no estado de Santa Catarina, mapeando ações e promovendo cursos de capacitação para que os profissionais possam atuar junto à habitação da população de baixa renda. Ressalta-se, ainda, no ano de 2020, a promoção de editais de patrocínio a ações de enfrentamento dos efeitos da pandemia de COVID-19 pelo CAU em diversos estados brasileiros, uma vez que a situação perpassa a questão da salubridade nos ambientes residenciais, principalmente.

Voltando-se para a discussão em torno dos municípios analisados, chamaram atenção, durante a pesquisa, os entraves encontrados para a criação de um programa de ATHIS no município de Curitiba, uma vez que o mesmo possui certa tradição e pioneirismo em diversos aspectos do planejamento urbano. É possível ter acesso, no site da Câmara de Vereadores, à tramitação de diversos projetos de lei em andamento ou arquivados, sendo que todos os projetos já elaborados até o momento para implantação de um programa de ATHIS na cidade foram arquivados pelo poder legislativo. Em compensação, no caso de Salvador, ações de ATHIS já ocorriam antes mesmo da aprovação da Lei Federal, sendo confirmadas no Plano Diretor da cidade não só como diretrizes para a política urbana, como, também, um meio de participação popular e de educação para a cidadania.

Estes casos levam a pensar se há, de fato, um desinteresse político pela questão da assistência técnica ou se a "ausência" de recursos para as ações é o fator mais preponderante para a sua efetivação. Se não 


\section{SÃO PAULO $15 \sim 17 \cdot$ LISBOA $25 \sim 26$ JUN 2020}

houverem propostas, projetos e programas que demandem os recursos, estes não serão utilizados. Destacase aqui, em um momento em que a pandemia de COVID-19 se alastra pelo país, a urgente necessidade de políticas públicas voltadas para melhorias no espaço habitado da grande maioria da população brasileira, principalmente a população de baixa renda. Um estudo realizado em 2020, pelo site Medida SP, cruzou dados de mais de 3 mil mortos pela COVID-19 na Grande São Paulo com seus CEPs, e constatou que 66\% das vítimas viviam em bairros em que a renda média estava abaixo de $R \$ 3$ mil, sendo que nas regiões com renda superior a $\mathrm{R} \$ 19$ mil, houve registro de $1 \%$ das mortes. Espaços insalubres, número excessivo de habitantes por metro quadrado e ausência de infraestrutura urbana e saneamento básico são componentes críticos das condições de vida nas cidades brasileiras há décadas, e a pandemia atual exacerba problemas históricos das cidades brasileiras e as condições de moradia da maioria da população.

Longe de se esgotar o estudo do tema, recomenda-se uma exploração mais profunda de como a ATHIS tem sido abordada em esferas municipais. Esta pesquisa se limitou a informações divulgadas online, portanto há possibilidade de se encontrar outros planos diretores que contemplem a assistência técnica como diretriz da política urbana. Ressalta-se, também, que não foram analisados os Planos Municipais de Habitação dos referidos municípios, o que poderia fornecer um maior panorama para as análises.

\section{BIBLIOGRAFIA}

ALVIM, A. T. B.; CASTRO, L. G. R. (org.) (2010) Avaliação de políticas urbanas - contexto e perspectivas. São Paulo: Ed. Mackenzie, Ed. Romano Guerra.

BRASIL. Lei Federal no 10.257 (2001) Regulamenta os arts. 182 e 183 da Constituição Federal, estabelece diretrizes gerais da política urbana e dá outras providências.

BRASIL. Lei Federal $n^{\circ} 11.888$ (2008) Assegura às famílias de baixa renda assistência técnica pública e gratuita para o projeto e a construção de habitação de interesse social e altera a Lei no 11.124 , de 16 de junho de 2005.

CARVALHO, C. S.; ROSSBACH, A. (orgs.) (2010) O Estatuto da Cidade comentado. São Paulo: Ministério das Cidades: Aliança das Cidades.

SABOYA, R. T. (2006) Planos diretores como instrumento de orientação das ações de desenvolvimento urbano. Arquitextos (São Paulo), 074.05.

SANTOS, J. S.; GONÇALVES, T. S. (2015) Assistência Técnica como política pública: o caso do Escritório Público de Salvador. Revista Campo do Saber (São Paulo), v. 1, n. 2.

STEPHAN, Í.; ARANTES, P. T. L.; FIALHO, B. C.; REIS, L. F.; LOPES, C. S. (2008) Participação popular e cooperação intermunicipal: Os Planos Diretores de Cruzília e Minduri MG. Arquitextos (São Paulo), 100.03.

\section{Fontes eletrônicas}

CAU/SC - Conselho de Arquitetura e Urbanismo de Santa Catarina. Plano Estratégico da Implantação da Assistência Técnica em Habitação de Interesse Social: Diagnóstico. 2018. Disponível em: 


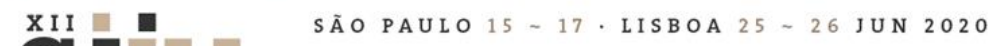

Seminário Internacional de

Seminario Internacional de Investigação em Urbanismo Investigación en Urbanismo

http://www.causc.gov.br/wp-content/uploads/2018/04/DIAGNOSTICO_FINAL_27032018.pdf (Acesso em 05 jul. 2018)

LOUREIRO, B. População mais pobre morre mais por Coronavírus em São Paulo. Medium. 11 jul. 2020. Disponível em: <https://medium.com/medidasp/popula\%C3\%A7\%C3\%A3o-mais-pobre-morre-mais-porcoronav\%C3\%ADrus-em-s\%C3\%A3o-paulo-443c3f20c986>. Acesso em: 08 ago. 2020.

SANSON, T. Assistência técnica habitação de interesse social [mensagem pessoal]. (Mensagem recebida por<maressa.fs@gmail.com> em 10 abr. 2018). 